\title{
Treasure Hunter Game Buah Maja Menggunakan Scirra Construct 2
}

\author{
Ade Bastiana $^{\mathrm{a}}$, Dadan Zaliluddin ${ }^{\mathrm{b}}$, Devi Sukrisna ${ }^{\mathrm{c}}$ \\ a,b,c,Program Studi Informatika Universitas Majalengka, Jl. KH. Abdul Halim 103 Majalengka, West Java, Indonesia \\ "correspondence email : bastiandicaprio@gmail.com ${ }^{\mathrm{a}}$, dadanzuu@domain.com ${ }^{\mathrm{b}}, \underline{\text { devisukrisna@gmail.com }}^{\mathrm{c}}$
}

\begin{abstract}
Majalengka is one of the regencies located in West Java Province. With the diversity of cultures and tourist attractions in Majalengka, the author intends to make a game that can accommodate several aspects of Majalengka so that it can be better recognized by the public, especially the Majalengka community itself. This research aims to introduce Majalengka to the outside community and the Majalengka community itself, through Majalengka icons and their natural wealth in the form of legendary Gincu and Maja Fruit. The system development method used is a development method using the MDLC (Multimedia Development Life Cycle) method. Questionnaires were given to people who had tried playing the Treasure Hunter Buah Maja, a questionnaire was made aimed at finding out the people's response to the game. With a result of $77.5 \%$, the community stated when they first tried the application to be easy to use. $80.8 \%$ of the people expressed interest in using the Treasure Hunter Buah Maja game. And as much as $85 \%$ of the people stated that this game was quite entertaining.
\end{abstract}

Index Terms-Game, Multimedia Development Life Cycle, Scirra Costruct 2.

Abstrak-Majalengka merupakan salah satu Kabupaten yang terletak di Propinsi Jawa Barat. Dengan beragamnya kebudayaan dan tempat wisata didaerah Majalengka, penulis bermaksud membuat sebuah Game yang dapat menampung beberapa aspek tentang Majalengka agar dapat lebih dikenali oleh masyarakat luas, khususnya masyarakat Majalengka itu sendiri. Penelitian ini bertujuan untuk mengenalkan Majalengka kepada masyarakat luar maupun masyarakat Majalengka itu sendiri, melalui ikon-ikon Majalengka dan kekayaan alamnya berupa buah Mangga Gincu dan Buah Maja yang melegenda. Metode pengembangan sistem yang digunakan ini adalah metode pengembangan dengan menggunakan metode MDLC (Multimedia Development Life Cycle). Kuesioner diberikan kepada masyarakat yang telah mencoba memainkan Game Treasure Hunter Buah Maja, kuesioner dibuat bertujuan untuk mengetahui tanggapan masyarakat terhadap game tersebut. Dengan hasil sebesar $77,5 \%$ masyarakat menyatakan saat pertama kali mencoba aplikasi mudah digunakan. Sebesar 80,8 \% masyarakat menyatakan tertarik menggunakan game Treasure Hunter Buah Maja. Dan sebesar $85 \%$ masyarakat menyatakan bahwa game ini cukup menghibur.

Kata Kunci-Game, Multimedia Development Life Cycle, Scirra Construct 2.

\section{PENDAHULUAN}

Seiring perkembangan teknologi informasi, pengembangan game menggunakan prospek yang luar biasa. Game yang merupakan salah satu industri besar di dunia saat ini, menawarkan banyak peluang dalam industrinya. Pada website resmi Asosiasi Game Indonesia, terdapat 122 pengembang game yang terdaftar sebagai anggota di Asosiasi Game Indonesia. Game (khususnya game edukasi) berbasis komputer saat ini telah menjadi trend yang menyebar luas. Banyak penelitian telah menyimpulkan tentang manfaat belajar dengan game edukatif dengan lebih banyak pendekatan tradisional [1]. Meskipun pasti ada alasan untuk kepuasan bermain game, dan banyak teknologi pendidikan semakin menyelidiki potensi permainan untuk belajar baik secara tradisional maupun berbasis komputer. [2]

Kata Game berasal dari bahasa Inggris. Dalam kamus bahasa Indonesia istilah "Game" adalah permainan. Permainan merupakan bagian dari bermain dan bermain juga bagian dari permainan keduanya saling berhubungan. Permainan dalam hal ini merujuk pada pengertian kelincahan intelektual (Intellectual Playability Game) yang juga bisa diartikan sebagai arena keputusan dan aksi pemainnya. Dalam game, ada target - target yang ingin dicapai pemainnya. Permainan adalah kegiatan yang kompleks yang didalamnya terdapat peraturan, bermain dan budaya. Sebuah permainan adalah sebuah sistem dimana pemain terlibat dalam konflik buatan. Disini pemain berinteraksi dengan sistem dan konflik dalam permainan merupakan rekayasa atau buatan. Dalam permainan terdapat peraturan yang bertujuan untuk membatasi perilaku pemain dan menentukan permainan [3].

Bermain atau game pada dasarnya memiliki dua pengertian yang harus dibedakan. Bahwa bermain menurut pengertian pertama dapat bermakna sebagai sebuah aktifitas bermain yang murni mencari 
kesenangan tanpa mencari menang kalah (play). Sedangkan pengertian yang kedua, sebagai aktivitas bermain yang dilakukan dalam rangka mencari kesenangan dan kepuasan, namun ditandai dengan adanya pencarian menang-kalah (game). Bermain sebagai game, kesenangan dan kepuasan yang diperoleh seseorang harus melibatkan kehadiran orang lain [4]. Game dapat menjadi sarana hiburan sekaligus belajar bagi penggunanya. Dengan adanya game, dapat meningkatkan pengetahuan dan logika penggunanya. Game dapat dimanfaatkan dalam hampir disegala aspek, salah satunya pada aspek pengenalan suatu daerah.

Majalengka merupakan sebuah daerah yang gencar melakukan pengenalan wisata dan budayanya ke ranah publik. Dinas Pariwisata dan Kebudayaan (Disparbud) Majalengka meresmikan kalender event 2018, dalam kegiatan Majalengka Weekend Expo dan Pameran Wisata Ekonomi Kreatif dan Budaya di lapangan Pujasera. Kepala Disparbud H. Gatot Sulaeman, A.P., M.Si. mengatakan, "Tujuan kegaiatankegiatan itu untuk promosi dan meningkatkan kualitas pariwisata dan kebudayaan yang ada di Kabupaten Majalengka. BIJB akan menjadi magnet bagi para wisatawan lokal maupun mancanegara, sehingga upaya promosi dan peningkatan kualitas pariwisata akan terus kita tingkatkan." Dikutip dari radarcirebon.com Senada dengan pernyataan Kepala Disparbud tersebut pengembangan sebuah Game yang dapat menampung beberapa aspek tentang Majalengka diperlukan agar dapat lebih dikenali oleh masyarakat luas, khususnya masyarakat Majalengka itu sendiri. Inspirasi dari judul game ini adalah dari cerita legenda buah maja yang konon menjadi cikal bakal nama Majalengka.

Game builder Construct 2 sebenarnya dirancang untuk game berbasis 2D. Dengan menggunakan Construct 2, pengembang permainan dapat mempublishnya ke beberapa platform seperti HTML 5 website, Google Chrome Webstore, Facebook, Phonegap (Android), Windows Phone, Windows 8. Pada Construct 2 telah disediakan 70 visual effect yang menggunakan engine WebGL. Selain itu juga dilengkapi dengan 20 built-in plugin dan behavior (perilaku objek) sehingga kita bisa membuat sprite, objek teks, mengkoneksikan dengan facebook, menambah musik, memanipulasi penyimpanan data game dan lain sebagainya.

Pemanggilan fungsi-fungsi di Construct 2 dilakukan dengan menggunkan pengaturan Events yang telah disediakan. Events merupakan pilihan-pilihan action dan kondisi yang akan menjadi nyawa dalam game, sehingga game akan berjalan sesuai dengan yang diinginkan. Karena berbasis HTML 5, maka preview saat running ketika ingin mencoba game dapat dilakukan pada browser (localhost).

\section{METODE}

1. Perancangan Alur Games

Perancangan sistem mempunyai dua tujuan yaitu memenuhi kebutuhan kepada pemakai (user) dan untuk memberikan gambaran yang jelas serta rancang bangun yang lengkap kepada pemrogram (developer) dan ahli teknik lainnya yang terlibat dalam pembuatan sistem tersebut.

Pada tahap perancangan ini dibuatkan alur aplikasi Game Treasure Hunter Buah Maja yang menggambarkan akses yang dilakukan user, alur sistem aplikasi game secara umum sebagai berikut :

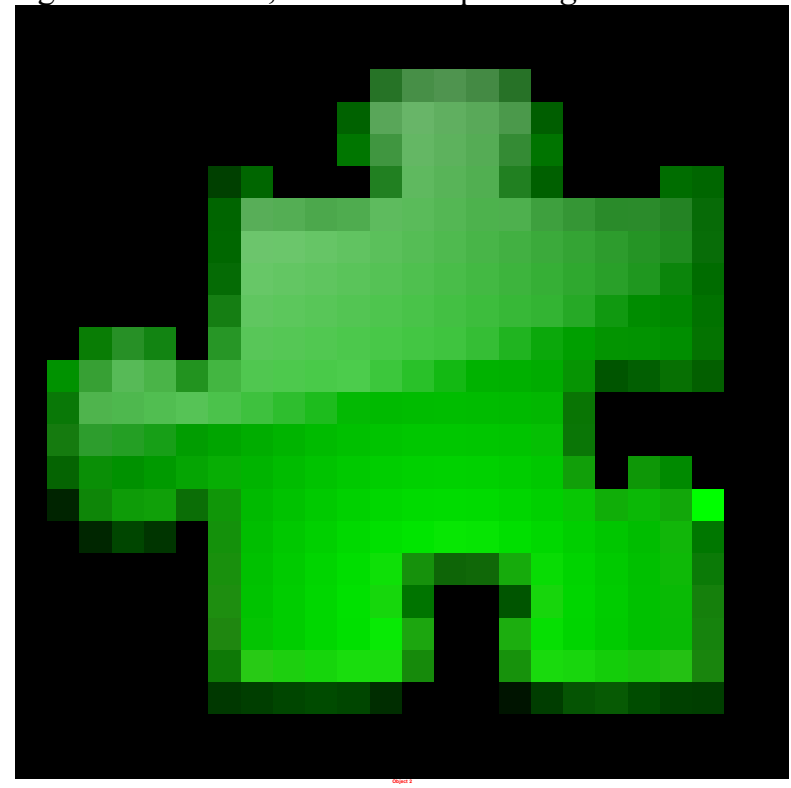

Gambar 1. Flowchart Alur Game Treasure Hunter Buah Maja 


\section{Gameplay}

Untuk menjalankan game ini tidak memerlukan alat bantu lain hanya menggunakan smartphone berbasis android yang telah ditetapkan pada software requitment penerapan game ini. Aturan untuk memainkan game ini sangat sederhana pemain hanya diminta menyentuh tombol yang terdapat pada layar game untuk melompat mendapatkan buah gincu dan ikon serta menghindari rintangan agar tidak mengurangi helt dan gameover. Setiap 5 buah gincu yang didapat akan menambah 1 nyawa. Untuk menyelesaikan level diharuskan melakukan intruksi yang diberikan untuk membuka level selanjutnya.

2. Perancangan Asset Games

Dalam game terdapat beberapa asset yang harus dibuat, seperti karakter, musuh, rintangan, music dan lain sebagainya, berikut adalah asset game yang dibutuhkan dalam pembuatan Game Treasure Hunter Buah Maja :

a. Karakter

Karakter dalam game ini hanya ada satu yaitu "Asep". Asep sendiri hanya bisa berlari, mengambil item dan menghindari rintangan dengan melompatinya, membunuh musuh dengan cara melompat dan menimpa diatasmya, untuk sketsa dapat dilihat pada gambar 2 .

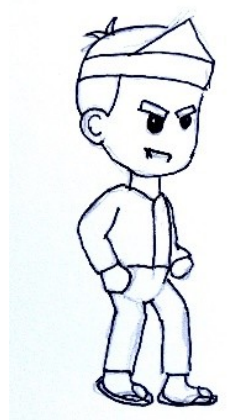

Gambar 2. Sketsa Karakter Asep

b. Musuh dan Rintangan

Musuh dan rintangan ini ada di setiap level masing-masing akan menghilangkan satu nyawa dari pemain. Dan rintangan akan langsung membuat permainan berakhir. Musuh bisa bergerak secara horizontal, vertical, bahkan diagonal untuk sketsa dapat dilihat pada dibawah :

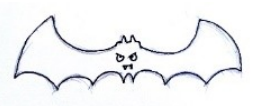

Gambar 3. Musuh Kelelawar

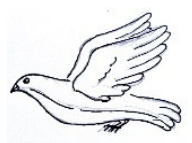

Gambar 5. Musuh Elang

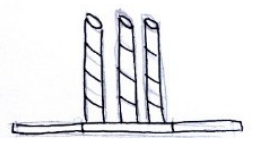

Gambar 7. Rintangan Bambu Runcing

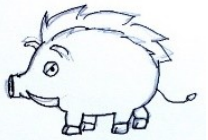

Gambar 4. Musuh Babi Hutan

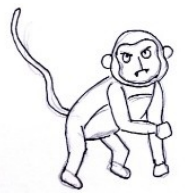

Gambar 6. Musuh Kera

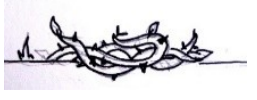

Gambar 8. Rintangan

Tanaman Beracun

c. Item

Setiap asset buah atau kunci akan memberikan 1 poin pada saat pemain mengambilnya atau melewatinya. Poin tersebut akan ditampilkan di papan skor, asset dapat dilihat pada gambar dibawah: 


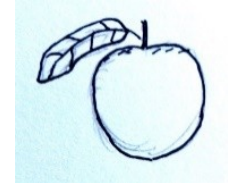

Gambar 9. Buah Gincu

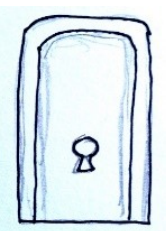

Gambar 11. Pintu

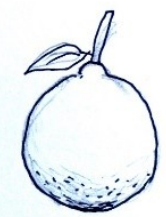

Gambar 13. Harta Buah Maja

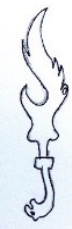

Gambar 10. Kujang

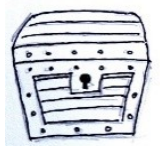

Gambar 12. Perti Harta

Buah Maja

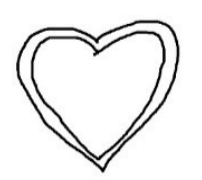

Gambar 14. Nyawa

4. Perancangan Storyboard

Pada perancangan Storyboard ini dibuat untuk menggambarkan kepada pengguna dalam perubahan alur aplikasi game sehingga pengguna dapat mengetahui secara jelas alur yang terdapat pada aplikasi game tersebut secara jelas. Dibawah ini adalah Storyboard yang dibuat :

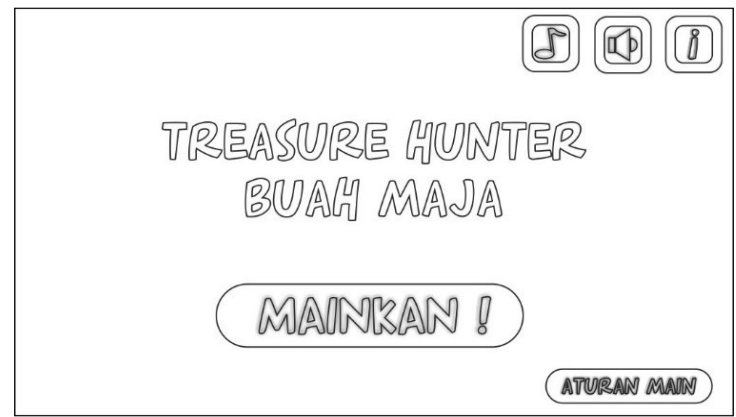

Gambar 15. Rancangan Splash Screen

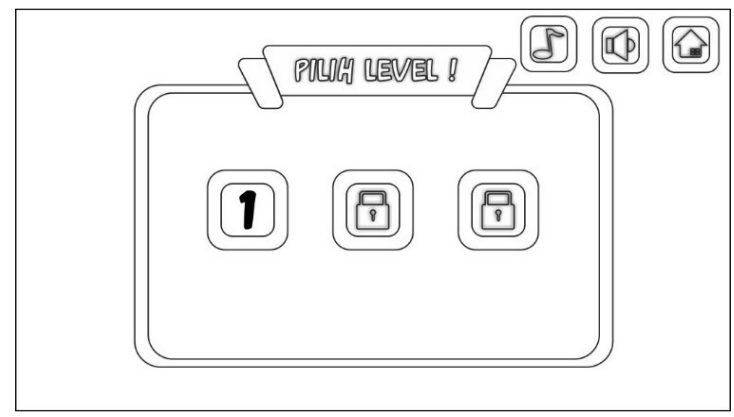

Gambar 16. Rancangan Pilih Level 


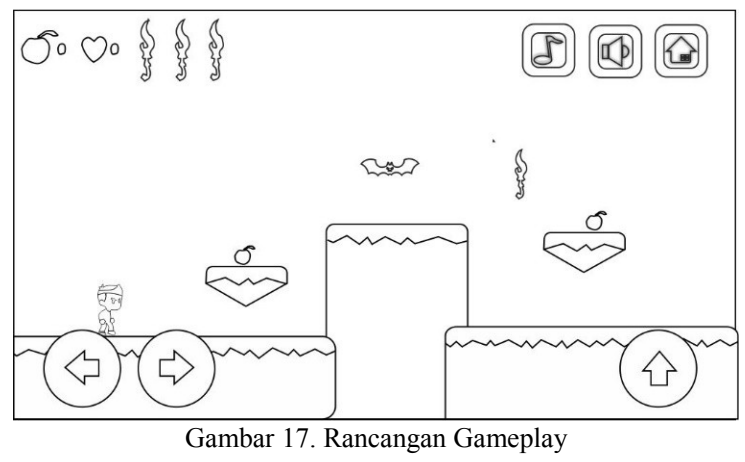

\section{IMPLEMENTASI}

Berikut adalah beberapa tampilan Interface yang sudah dirancang yaitu berupa screenshot aplikasi game sesuai dengan rancangan storyboard :

1) Tampilan Interface Halaman Utama

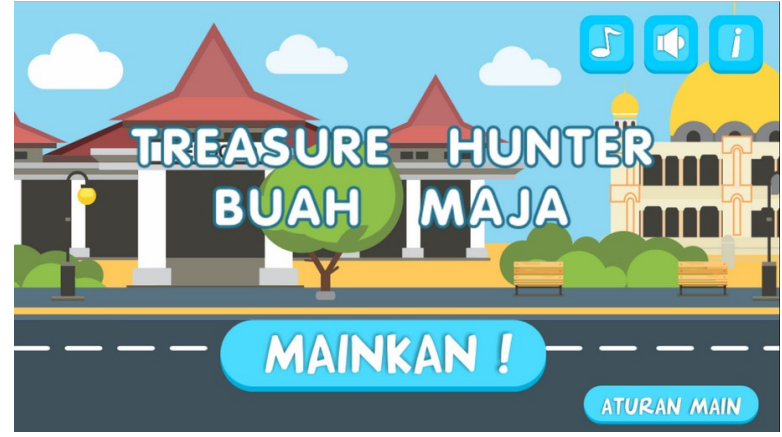

Gambar 18. Tampilan Menu Utama

2) Tampilan Interface Pilih Level

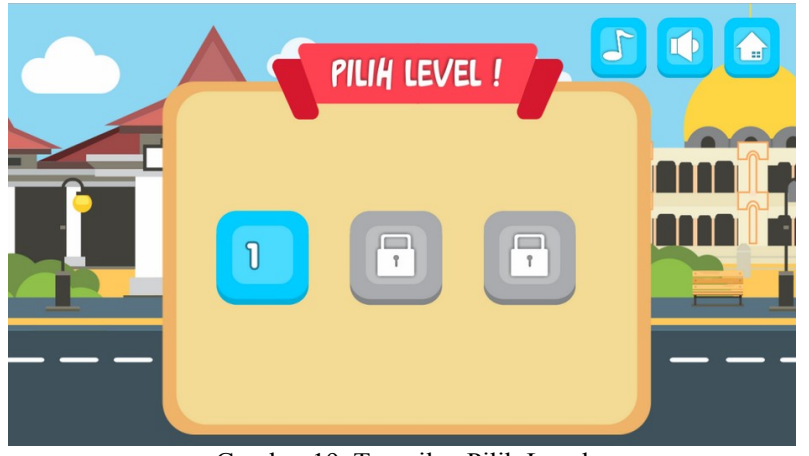

Gambar 19. Tampilan Pilih Level

3) Tampilan Interface Gameplay

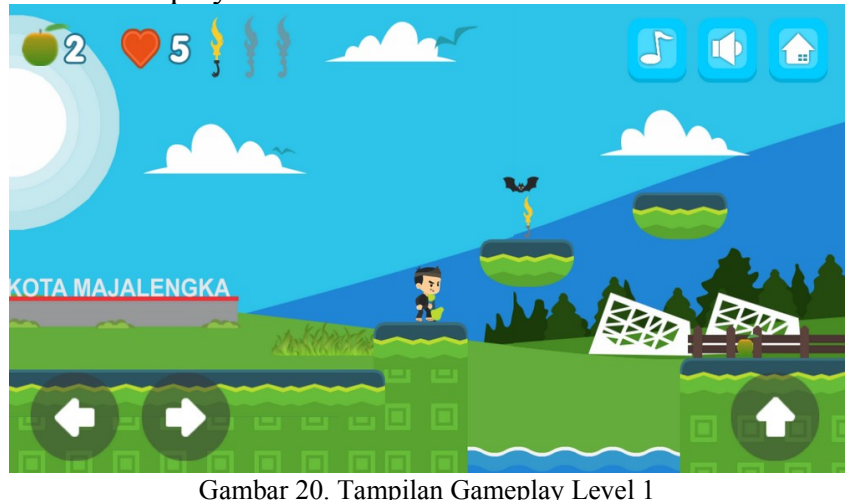




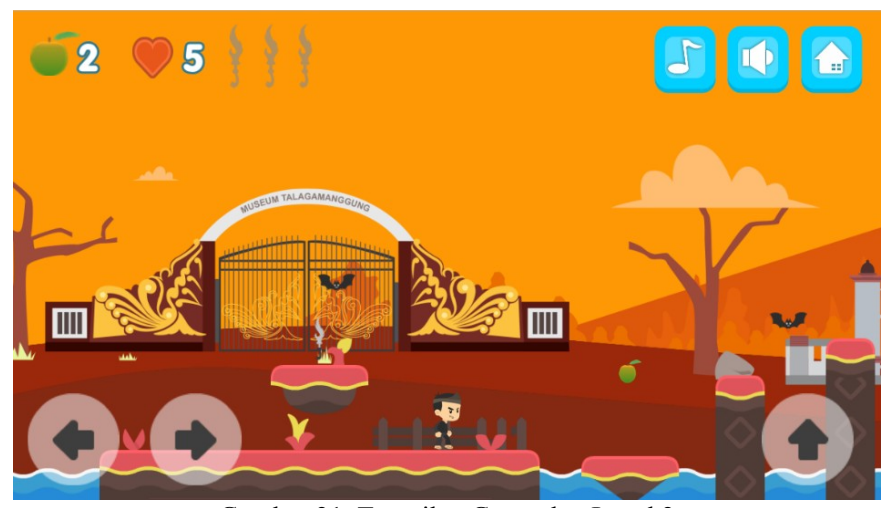

Gambar 21. Tampilan Gameplay Level 2

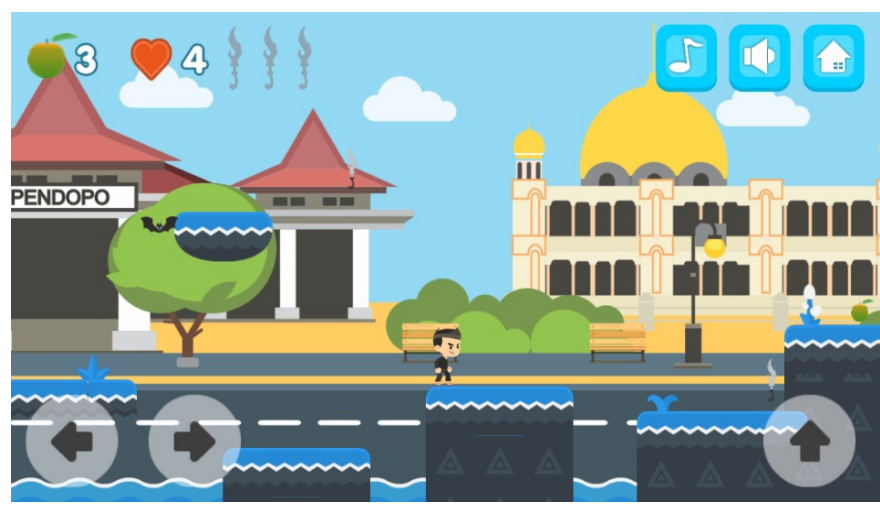

Gambar 22. Tampilan Gameplay Level 3

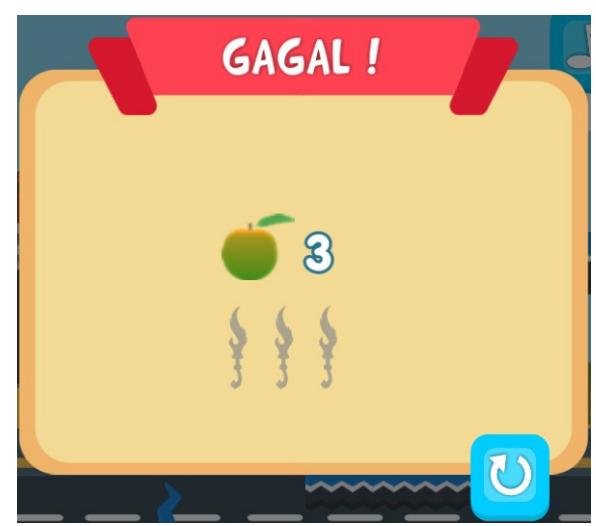

Gambar 23. Tampilan Player Gagal

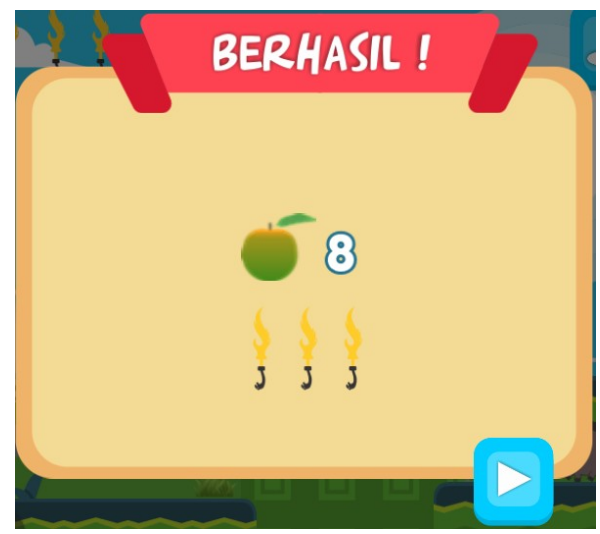

Gambar 24. Tampilan Player Berhasil Level 1 \& 2 


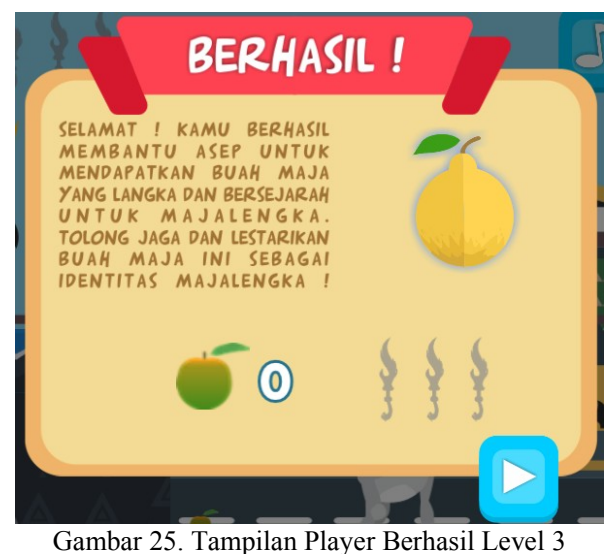

\section{IV.KESIMPULAN}

Kuesioner diberikan kepada masyarakat yang telah mencoba memainkan Game Treasure Hunter Buah Maja, kuesioner dibuat bertujuan untuk mengetahui tanggapan masyarakat terhadap game tersebut. Kuesioner ini ini terdiri dari 10 buah pernyataan dengan 4 kategori skor tanggapan. Kategori skornya yaitu Sangat Setuju (SS) dengan skor 4, Setuju (S) dengan skor 3, Kurang Setuju (KS) dengan skor 2 dan Tidak Setuju (TS) dengan skor 1. Kuisoner ini diberikan kepada 30 orang yang yang telah mencoba memainkan game Treasure Hunter Buah Maja. Untuk mengetahui rekapitulasi tanggapan masyarakat untuk setiap pernyataan pada kuesioner Game Treasure Hunter Buah Maja dapat dilihat pada Tabel 1 berikut ini :

\begin{tabular}{clcc}
\multicolumn{2}{c}{ Tabel 1 Rekapitulasi Kuisioner Tanggapan Masyarakat } & Skor Rata-rata & Presentase \\
\hline No & \multicolumn{1}{c}{ Pernyataan } & 3,10 & $77,5 \%$ \\
\hline 1 & Saat pertama kali mencoba aplikasi mudah digunakan & 3,40 & $85 \%$ \\
\hline 2 & Simbol-simbol dalam Game mudah dikenali/ dipahami & 3,43 & $85,8 \%$ \\
\hline 3 & Teks dalam aplikasi mudah dibaca & 3,30 & $82,5 \%$ \\
\hline 4 & Mudah mencari tombol yang saya butuhkan & 3,23 & $80,8 \%$ \\
\hline 5 & Saya tertarik menggunakan aplikasi ini & 3,40 & $85 \%$ \\
\hline 6 & Game ini cukup menghibur & 2,80 & $70 \%$ \\
\hline 7 & Tingkat kesulitan tiap level sudah cukup & 3,60 & $90 \%$ \\
\hline 8 & Desain pemilihan warna pada tampilan Game cukup baik & 3,23 & $80 \%$ \\
\hline 9 & Suara yang dikeluarkan pada Game sudah cukup jelas terdengar & 3,47 & $86,7 \%$ \\
\hline 10 & Ikon-ikon Majalengka pada background Game dapat dikenali & 3,30 & $77 \%$ \\
\hline & Rata-rata &
\end{tabular}

Berdasarkan hasil pengujian dan implementasi yang sudah dilakukan, maka kesimpulan dari penelitian dengan judul "Rancang Bangun Aplikasi Game Treasure Hunter Buah Maja dengan Menggunakan Scirra Construct 2" yaitu sebagai berikut:

1) Game Treasure Hunter Buah Maja ini dikembangkan dengan software Scirra Construct 2 dan Corel Draw X7 dengan menggunakan metode Multimedia Development Life Cycle (MDLC);

2) Berdasarkan hasil survei dengan Kuesioner, sebagian besar masyarakat yang mengikuti survei memberi respon positif terhadap Game Treasure Hunter Buah Maja dengan persentase rata-rata sebesar $77 \%$.

\section{UCAPAN TERIMA KASIH}

Terima kasih pada Dinas Pariwisata dan Kebudayaan Kabupaten Majalengka Jawa Barat yang telah mendukung pengembangan games Buah Maja ini hingga membawa karya games Buah Maja ini ke berbagai event Expo seperti My Create Festival 2018, Gedung Sate Festival 2018, dan Festival Gunung Ciremai 2018. Terima kasih juga pada Universitas Majalengka yang telah membawa karya games Buah Maja ini ke Pameran Inovasi LLDIKTI Wilayah IV 2018. 


\section{DAFTAR PUSTAKA}

[1] Gee, J. P. (2003). What video games have to teach us about learning and literacy (1st ed.). New York: Palgrave Macmillan.

[2] Bruce M. McLaren, Deanne M. Adams, Richard E. Mayer and Jodi Folizzi (2017). A Computer-Based Game that Promotes Mathematics Learning More than a Conventional Approach. International Journal of Games-Based Learning Volume 7 Issue 1 January-March 2017.

[3] Rosidi Zamroni, M dkk. 2013. Rancang Bangun Aplikasi Permainan Untuk Pembelajaran Anak Menggunakan HTML 5. Volume 5 Nomor 2. Universitas Islam Lamongan.

[4] Saputro, Dwi. 2015. Pembuatan Game Edukasi "Bahasa Inggris Anak" Berbasis Android Menggunakan Construct 2. Surakarta: Universitas Surakarta.Minat Khusus Di Gunung.

[5] Solihin, Miftahus dan Kemal Farouq. 2016. Game Pass-Puzz dengan Construct 2. JOUTICA-PRESS. Universitas Islam Lamongan.

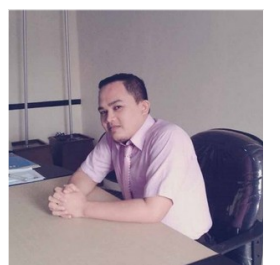

Ade Bastian, lahir di Majalengka tanggal 15 Februari tahun 1987. Menyelesaikan pendidikan Magister Sistem Informasi di STMIK LIKMI Bandung, Indonesia dengan gelar M.Kom.

Dia bekerja sebagai KETUA Program Studi Informatika Fakultas Teknik Universitas Majalengka yang beralamat di Jalan K.H. Abdul Halim No. 103 Kabupaten Majalengka, Provinsi Jawa Barat, Indonesia. Penelitian yang sudah dipublikasi diantaranya, "Solution Search Simulation The Shortest Step On Chess Horse Using Algorithm" di Jurnal International Journal of Artificial Inteligence Research (IJAIR), "Penerapan Algoritma K-Means Clustering Analysis Pada Penyakit Menular Manusia (Studi Kasus Kabupaten Majalengka" di Jurnal Sistem Informasi (JSI), dan "Pengembangan SmartCam Auto Motion Detect dan Short Message Service (SMS) Alert" di Jurnal Ilmiah Teknologi Informasi Terapan (JITTER).

Penelitian dengan judul "Treasure Hunter Game Buah Maja Menggunakan Scirra Construct 2"ini disusun Ade Bastian, S.T., M.Kom., Dadan Zaliluddin, S.T., M.Kom. dan Devi Sukrisna. 